\title{
Intimate partner violence, common mental disorders and household food insecurity: an analysis using path analysis
}

\author{
Claudia Leite de Moraes ${ }^{1,2, *}$, Emanuele Souza Marques ${ }^{1}$, Michael Eduardo \\ Reichenheim ${ }^{1}$, Marcela de Freitas Ferreira ${ }^{1}$ and Rosana Salles-Costa ${ }^{3}$ \\ 'Institute of Social Medicine, Rio de Janeiro State University, Rua Francisco Xavier 524, $7^{\circ}$ andar - bloco D, \\ CEP 20550-900 Maracanã, Rio de Janeiro, Brazil: ${ }^{2}$ Family Health Program, Estácio de Sá University, Rio de \\ Janeiro, Brazil: ${ }^{3}$ Nutrition Institute Josué de Castro, Federal University of Rio de Janeiro, Rio de Janeiro, Brazil
}

Submitted 17 June 2015: Final revision received 9 March 2016: Accepted 4 April 2016: First published online 23 May 2016

\begin{abstract}
Objective: To investigate the direct and indirect associations between psychological and physical intimate partner violence and the occurrence of common mental disorders (CMD) and how they relate to the occurrence of household food insecurity (HFI).

Design: This was a population-based cross-sectional study. Intimate partner violence was assessed using the Brazilian version of the Revised Conflict Tactics Scale (CTS2) and HFI was assessed using the Brazilian Food Insecurity Scale. The propositional analytical model was based on a review of the literature and was tested using path analysis.

Setting: Duque de Caxias, Greater Rio de Janeiro, Brazil (April-December 2010). Subjects: Women ( $n$ 849) who had been in a relationship in the 12 months preceding the interview.

Results: Both psychological and physical violence were found to be major risk factors of HFI. Psychological violence was associated with HFI indirectly via physical violence and CMD, and directly by an unidentified path. The effects of physical violence seemed to be manifested exclusively through CMD. Most of the variables in the propositional model related to socio-economic position, demographic characteristics, degree of women's social support and partner alcohol misuse were retained in the 'final' model, indicating that these factors contribute significantly to the increased likelihood of HFI.

Conclusions: The results reinforce the importance of considering domestic violence and other psychosocial aspects of family life when implementing interventions designed to reduce/eradicate HFI.
\end{abstract}

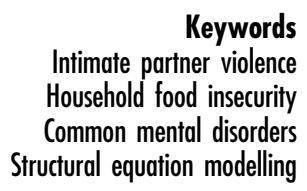

Reducing the number of people who suffer from hunger by 2015 was one of the UN Millennium Development Goals published in $2000^{(1)}$. Despite many global efforts to reduce the number of food-insecure households, the rise in food prices following the latest global economic crisis (2008-09) has prompted increased concern about this problem in different nations ${ }^{(2)}$. The alarming estimates published by a variety of institutions in recent years seem to justify this concern. According to the FAO, although the prevalence of estimated household food insecurity (HFI) may have decreased by $17 \%$ between 1990-92 and 2011-13, the state of affairs is still unacceptable because there are still approximately 842 million individuals living with food insecurity ${ }^{(3)}$.

In different parts of the world, several programmes have been devised to reduce the number of food-insecure and hungry people. Although these proposals have yielded some positive results, creating interventions based solely on the supply of financial resources to a vulnerable population group does not seem to have the power to completely eliminate the problem ${ }^{(4)}$. This has led some researchers to begin investigating whether other determinants beyond income could be involved that could therefore be the target of measures to tackle food insecurity ${ }^{(4-7)}$.

Some authors suggest that psychosocial factors and aspects of a couple's relationship could influence $\mathrm{HFI}^{(4,5,8-10)}$, but the number of studies investigating these factors is still limited. Only five studies have examined the impact of intimate partner violence (IPV) on HFI. Two used primarily qualitative methods ${ }^{(8,10)}$, whereas the other three were population-based epidemiological studies ${ }^{(4,5,11)}$.

One finding emerging from the qualitative studies concerns women's perceptions that the control exerted by their partners on the financial resources needed to buy food could be used as a form of $\operatorname{coercion}^{(8)}$. The other 
qualitative study showed that the stress caused by IPV contributed to a decrease in food intake, not only in the woman herself but in other family members as well. Many women have also stated that exposure to violence affects their mental health to the extent that they have given up their studies and jobs, putting a strain on the household budget and therefore the possibility of having a varied and sufficient diet ${ }^{(10)}$. These effects of IPV on women's mental health have been repeatedly highlighted by several authors $^{(12-14)}$ and by the WHO in its recent publication on the health effects of IPV ${ }^{(15)}$.

The three quantitative studies have suggested that under some circumstances, IPV could contribute to $\mathrm{HFI}^{(4,5,11)}$. One was a population-based epidemiological study conducted in the UK between 1999 and $2006^{(4)}$. That follow-up study involving 1116 families showed that domestic violence remained a risk factor for HFI after controlling for several confounders. A study conducted by Hernandez et al. ${ }^{(5)}$ on a sample of 1690 socially disadvantaged mothers of young children in twenty US cities reached the same conclusions. The authors also raised the possibility that the relationship between IPV and HFI could be mediated by maternal depression, which is consistent with what is proposed by the $\mathrm{WHO}^{(15)}$. However, the interpretation of their findings is somewhat limited because there was no analytical approach suitable to analyse the role of mediating variables. A more recent study conducted in Brazil also suggested an association between physical IPV and HFI ${ }^{(11)}$. In that study, couples reporting minor and severe physical IPV were more likely to experience HFI compared with those not reporting these types of IPV. Moreover, although touching on novel issues, none of the quantitative studies yielded new findings regarding the importance of the independent and separate roles of psychological and physical IPV in HFI.

The high prevalence of domestic violence worldwide and the severity of its impact on women's mental health $^{(12-14)}$ justifies testing whether these two phenomena jointly contribute to the explanatory models of HFI. The relevance of HFI per se, combined with the apparent inability of theoretical models confined to addressing socio-economic issues to fully consider the complexities involved, indicate that more studies are needed. Investigating to what extent and means different forms of IPV are related to the occurrence of HFI could facilitate the development of new proposals to prevent or mitigate this problem. The present study thus investigated how psychological and physical IPV, mental disorders and HFI are interrelated in the light of common antecedents and potential confounders.

\section{Methods}

\section{Study design and participants}

The current population-based cross-sectional study was conducted in Duque de Caxias, a municipality in Greater
Rio de Janeiro, Brazil. Data collection occurred from April to December 2010. Participants were selected by multiplestage cluster sampling (census blocks, permanent private households and individuals) using inverse sampling as the field strategy ${ }^{(16,17)}$. The study population comprised 849 female adolescents and adult women involved in an intimate relationship within the 12 months prior to the interview. Due to missing data, the number of individuals effectively participating in the analysis before imputation varied from 793 to 849 depending on the variable (see below). Information was obtained through face-to-face interviews with the female person in charge of buying and preparing meals. All interviews were held in a designated area without the presence of the partner. The participants were assured of their full anonymity and confidentiality. The study was approved by the Federal University of Rio de Janeiro research ethics committee (protocol number 73/2009) in accordance with the principles set forth in the Declaration of Helsinki.

\section{Theoretical model, variables and questionnaires}

Figure 1 presents the directed acyclic graph of the "propositional' model initially tested. Given the limited number of studies focusing specifically on the relationship between IPV and HFI, this model was developed based on knowledge about the impact of IPV on the mental health of women and the macro-structural factors related both to domestic violence and HFI. The model encompassed seven domains: socio-economic status, demographic characteristics and social support of the women, alcohol misuse by the partner, psychological and physical IPV, common mental disorders (CMD) in women and HFI. The path diagram moves from the left to the right, respecting the postulated hierarchical sequence of events. The related variables are described below, including definitions and the respective instruments used when applicable.

Women's socio-economic status was represented by two variables: an economic classification variable measured by the Brazilian Economic Classification Criterion and self-reported race/ethnicity. The Brazilian Economic Classification Criterion is a composite index consisting of several household assets, information on whether there is a domestic employee at home and the educational status of the main income earner ${ }^{(18)}$. As recommended, the index was categorized into five strata, ranging from the richest (A; high income) to the most disadvantaged group (E; very low income). Women's self-reported race/ ethnicity was analysed as a dichotomized variable: white $v$. non-white. This categorization aimed to represent the sociodemographic and cultural differences present in Brazilian society. Many studies have shown that compared with whites (mostly Caucasians from European background), non-whites (African descendants, Mestizos, Asians and South American native populations) have lower incomes, live in households with poorer sanitation and have a lower level of schooling ${ }^{(19)}$. 


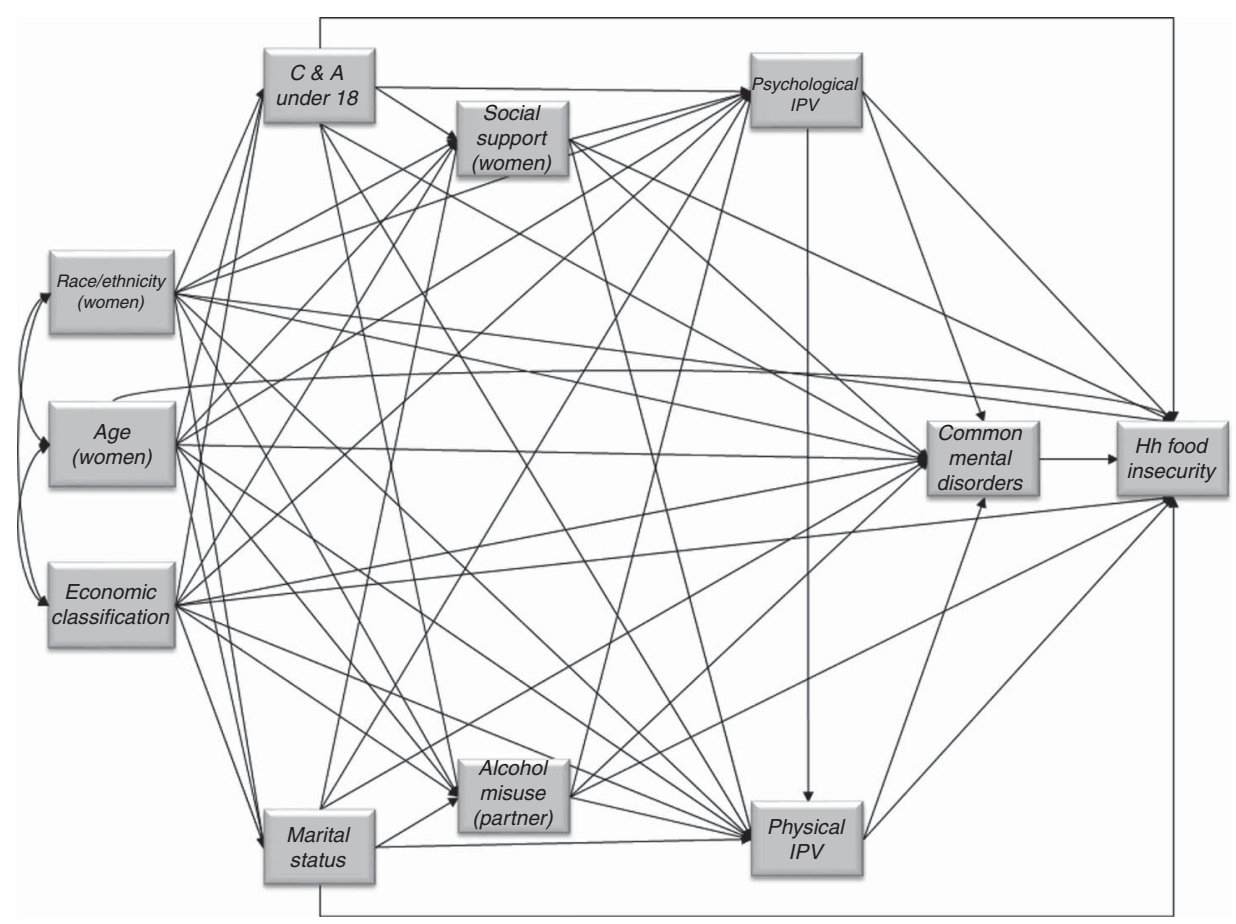

Fig. 1 Propositional model: directed acyclic graph of the relationships between intimate partner violence, common mental disorders and food insecurity ('Hh food insecurity', household food insecurity; 'Common mental disorders', common mental disorders in the woman; 'Psychological IPV', psychological intimate partner violence; 'Physical IPV', physical intimate partner violence; 'Alcohol misuse (partner)', alcohol misuse by the partner; 'Social support (women)', woman's social support; 'C \& A under 18', presence of children and adolescents under 18 years old in the household; 'Race/ethnicity (women)', woman's self-reported skin colour; 'Economic classification', Brazilian Economic Classification Criterion; 'Age (women)', woman's age)

The demographic variables comprised women's age, marital status and whether there were any children or adolescents under the age of 18 years old in the household. Age was analysed as a continuous variable and marital status as a binary variable (either married/cohabiting or single/ divorced/widowed). The presence of children and adolescents under 18 years old was also dichotomized (yes or no).

Social support perceived by the women was assessed through the Portuguese version of the material support subscale developed for the Medical Outcomes Study ${ }^{(20,21)}$. This subscale covers the respondents' perceptions of four types of third-party help received in daily activities and in case of illness. The score ranges from 4 to 20 and is calculated as the sum of the responses to each of the component items $(1=$ never, $2=$ rarely, $3=$ sometimes, $4=$ almost always, 5=always).

Alcohol misuse by the woman's partner was measured through the Portuguese version of the CAGE questionnaire (Cut-down; Annoyed; Guilty; Eye-opener) ${ }^{(22,23)}$ administered to the women by proxy. The CAGE consists of four yes/no questions covering the social repercussions of alcohol misuse. In line with the literature, positive answers to two or more items indicated potential alcohol misuse in the descriptive analysis; whereas the raw score (0-3) was employed in the path analyses.

The Portuguese version of the Revised Conflict Tactics Scale (CTS2) ${ }^{(24-27)}$ was used to assess IPV. Only two of the five available subscales were of interest in the present study: psychological and physical violence. The subscale on psychological IPV comprises eight dichotomous items (whether the event has ever happened or not) relating to women as perpetrators and/or victims. Raw scores thus range from 0 to 16 . Likewise, the physical IPV subscale consists of twelve items, with a respective score varying from 0 to 24 . For analysis purposes, the few individuals with scores of 10 or above were grouped into a single category. IPV was dichotomized for descriptive purposes; a positive response to at least one of the items in the respective subscale defined a positive case. Raw scores per subscale were used in the main path analyses. The recall period covered the 12 months prior to the interview.

The evaluation of CMD used the Portuguese version of the twelve-item General Health Questionnaire $(\mathrm{GHQ}-12)^{(28)}$. The items on this questionnaire measure how often symptoms occurred in the preceding two weeks. As the items contain four response options, the total score varies from 12 to 48 . Women scoring 3 or above were defined as possible cases of CMD for descriptive purposes $^{(29)}$.

HFI was measured using the Brazilian Food Insecurity Scale ${ }^{(30)}$. This version has been cross-culturally adapted from the US Household Food Security Survey Module $(\mathrm{HFSSM})^{(31)}$, which is regarded as the best epidemiological instrument currently available ${ }^{(32)}$. This version of the 
Brazilian scale encompassed fifteen dichotomous items on food insecurity experienced in the previous 3 months, upon which households were classified into four groups: food and nutritionally secure (adult-only and child and adolescent (C\&A) scales, score $=0)$, mildly food insecure (adult-only scale, score $=1-5$; C\&A scale, score $=1-3$ ), moderately food insecure (adult-only scale, score $=6-10$, C\&A scale, score $=4-6$ ) and severely food insecure (adultonly scale, score $=11-15$, C\&A scale, score $=7-8)^{(30,33)}$. In the present study the latter two categories were grouped together. The main outcome was thus modelled as a threelevel variable.

\section{Statistical analysis}

As conveyed before, a multiple imputation procedure was first employed to address the missing data. Assuming a MAR (missing at random) pattern, twenty imputed databases were generated using Mplus $7.13^{(34)}$. These databases were subsequently exported to the statistical software package Stata 13 ('mi passive' command) for data managing and processing.

The modelling process used path analyses. As the distributions of the outcome variables differed according to the equations in the system, so too did the respective models. Returning to the variables in Fig. 1, the following models were used: 'Hh food insecurity', ordinal logit model; 'Common mental disorders', linear model; 'Psychological IPV', ordinal logit model; 'Physical IPV', ordinal logit model; 'Social support (women)', linear model; 'Alcohol misuse (partner)', ordinal logit model; 'C \& A under 18' and 'Marital status', logit model. Regarding the ordinal logit models, proportional odds assumptions were tested ahead of the main modelling process using the 'omodel' Stata command. Three variables from the directed acyclic graph were completely exogenous ('Race/ ethnicity (women)', 'Age (women)' and 'Economic classification') and therefore did not require a distributional specification.

The analyses employed the Mplus robust maximum likelihood estimator ${ }^{(34)}$. The fit of the model was evaluated using the Bayesian information criterion (BIC). The model with the lowest BIC value was considered the best fitting model $^{(35)}$.

The modelling process consisted of two steps. Starting with the 'propositional' model presented in Fig. 1, misspecifications that suggested paths to add or remove were assessed in the first stage. Modification indices provided by Mplus were scrutinized to this end. Re-specification occurred if the BIC value dropped after freely estimating the model with the suggested new path or with a removal. The decision to explore and retain/remove a path was also based on theoretical plausibility ${ }^{(36)}$.

The second stage involved systematically trimming nonsignificant paths, i.e. those involving coefficients with an estimated $P$ value of $>0 \cdot 05$. However, paths with $P$ values between 0.05 and $<0.1$ were preserved when they led to a significant reduction in the BIC value. This process respected the specific hierarchy of the initial 'propositional' model. The trimming process started on the left and moved to the right: (i) starting with all of the paths originating from the more distal variables ('Race/ethnicity (women)', 'Age (women)' and 'Economic classification'); (ii) moving to the first-level intermediate variables ('Marital status', 'C \& A under 18', 'Social support (women)' and 'Alcohol misuse (partner)'); (iii) progressing to the second-level intermediate variables ('Psychological IPV' and 'Physical IPV'); (iv) and finally from the most proximal variable ('Common mental disorders'). The overall process was stopped when no additional path was suggested, all remaining paths were statistically significant and the fit of the model was acceptable. This stage of the analysis was also conducted using Mplus version $7.13^{(34)}$.

\section{Results}

\section{Profile of the participants in the study}

As shown in Table 1, 39.4\% of the families were food insecure at the time of the interview and of those, over a quarter were classified as having moderate or severe food insecurity. Nearly three-quarters of the women reported having been involved in at least one episode of psychological violence and approximately a quarter reported at least one episode of intimate partner physical aggression in the 12 months prior to the interview. Of those reporting psychological violence, $41 \cdot 1 \%$ also stated experiencing physical violence in their relationships, $93.9 \%$ who alleged physical violence said that they had also suffered psychological violence. Approximately $80 \%$ of the women reported three or more symptoms of mental distress, $71 \cdot 1 \%$ belonged to the lower middle-income class (class C), just over a third of the women described themselves as white, and nine out of ten said they were in a stable relationship at the time of the interview. Most women were of childbearing age. Approximately two-thirds of the households had at least one child or adolescent, and $10 \cdot 3 \%$ of the partners were identified as potential misusers of alcohol.

\section{Main findings}

The 'propositional' model was first analysed with the covariance between the distal variables specified ('Race/ ethnicity (women)', 'Age (women)' and 'Economic classification') and without the path from 'Psychological IPV' to 'Physical IPV'. As all three covariances were largely nonsignificant at the conventional level $(P<0.05)$, the model was tested without the covariances involving exogenous variables. This reduced the BIC value by $32 \cdot 2 \%$ (from $28370 \cdot 241$ to $19244 \cdot 720$ ). Based on the indications from the modification indices, a path between the two types of violence was introduced, which again improved the fit of the model $(\mathrm{BIC}=19035 \cdot 174)$. In the second stage of the 
Table 1 Profile of the study population: women $(n 849)$ who had been in a relationship in the 12 months preceding the interview, Campos Elíseos, Duque de Caxias, Rio de Janeiro State, Brazil, 2010

\begin{tabular}{|c|c|c|c|}
\hline Variable & $n$ & $\%$ & $95 \% \mathrm{Cl}$ \\
\hline \multicolumn{4}{|l|}{ Household food insecurity } \\
\hline Food secure & 479 & $61 \cdot 6$ & $54 \cdot 3,68 \cdot 8$ \\
\hline Mildly food insecure & 261 & $27 \cdot 8$ & $22 \cdot 0,33 \cdot 6$ \\
\hline Severely and moderately food insecure & 94 & 11.6 & $6 \cdot 8,14.4$ \\
\hline \multicolumn{4}{|l|}{ Psychological intimate partner violence } \\
\hline No & 228 & $30 \cdot 6$ & $22 \cdot 9,38 \cdot 2$ \\
\hline Yes & 607 & $69 \cdot 4$ & $61 \cdot 7,77 \cdot 1$ \\
\hline \multicolumn{4}{|l|}{ Physical intimate partner violence } \\
\hline No & 569 & $73 \cdot 2$ & $64.9,81.4$ \\
\hline Yes & 266 & $26 \cdot 8$ & $18 \cdot 6,35 \cdot 1$ \\
\hline \multicolumn{4}{|l|}{ Common mental disorders } \\
\hline No & 166 & $17 \cdot 8$ & $13 \cdot 7,22 \cdot 7$ \\
\hline Yes & 656 & $82 \cdot 2$ & $77 \cdot 2,86 \cdot 3$ \\
\hline \multicolumn{4}{|l|}{ Economic classification* } \\
\hline B class (middle-income) & 50 & $3 \cdot 7$ & $1 \cdot 9,5 \cdot 6$ \\
\hline C class (lower middle-income) & 499 & $71 \cdot 1$ & $65 \cdot 2,77 \cdot 0$ \\
\hline $\mathrm{D}$ and $\mathrm{E}$ class (low-income and very low-income) & 244 & $25 \cdot 1$ & $19 \cdot 2,31 \cdot 1$ \\
\hline \multicolumn{4}{|l|}{ Race/ethnicity } \\
\hline White & 270 & $36 \cdot 1$ & $28 \cdot 1,44 \cdot 1$ \\
\hline Non-white & 572 & 63.9 & $55.8,71.9$ \\
\hline \multicolumn{4}{|l|}{ Marital status } \\
\hline Married/common-law union & 743 & 89.5 & $85 \cdot 3,93 \cdot 6$ \\
\hline Single/divorced/widow & 104 & $10 \cdot 5$ & $6 \cdot 4,14 \cdot 6$ \\
\hline \multicolumn{4}{|c|}{ Children or adolescents under 18 years old in the household } \\
\hline No & 173 & $32 \cdot 9$ & $24 \cdot 8,41 \cdot 1$ \\
\hline Yes & 676 & $67 \cdot 1$ & $58 \cdot 9,75 \cdot 2$ \\
\hline \multicolumn{4}{|l|}{ Woman's age (years) } \\
\hline $10-20$ & 26 & $1 \cdot 2$ & $0.3,2 \cdot 0$ \\
\hline $20-30$ & 245 & $21 \cdot 0$ & $16 \cdot 0,26 \cdot 0$ \\
\hline $30-40$ & 251 & $36 \cdot 8$ & $30 \cdot 3,43 \cdot 2$ \\
\hline $40-50$ & 199 & $20 \cdot 2$ & $16 \cdot 1,24 \cdot 2$ \\
\hline $50-60$ & 118 & $12 \cdot 7$ & $8 \cdot 7,16 \cdot 8$ \\
\hline$>60$ & 10 & $8 \cdot 1$ & $0.3,15 \cdot 8$ \\
\hline \multicolumn{4}{|l|}{ Partner's alcohol misuse } \\
\hline No & 746 & $89 \cdot 7$ & $85 \cdot 5,93 \cdot 8$ \\
\hline Yes & 90 & $10 \cdot 3$ & $6 \cdot 2,14 \cdot 4$ \\
\hline
\end{tabular}

*Brazilian Economic Classification Criterion ${ }^{(18)}$.

modelling process, several of the paths originally proposed were deleted because they proved statistically non-significant at the specified levels or failed to reduce the BIC value. According to the scheme described in the Methods section, the analysis took nine sequential steps to reach a simplified 'final' model.

Figure 2 shows the directed acyclic graph of this 'final' model. The estimates of each path are shown in Table 2 . Interestingly, HFI was associated with both psychological and physical violence. There was a direct path between psychological violence and HFI, indicating that part of this relationship may be mediated by factors not included in the model. In addition to this direct link, mediation through physical violence and CMD was also apparent. The association between physical violence and HFI seemed to occur exclusively through CMD. Notably, this relationship had to be smaller than the overall psychological IPV because the latter contained additional positive paths to the outcome. All estimates were adjusted for the other variables in the system and potential confounders in the process.
As conveyed in Fig. 2 and Table 2, in addition to the two types of violence and $\mathrm{CMD}$, there were also direct or indirect connections between the other antecedents and HFI. Considering only the direct path, food insecurity was approximately 6.6 times more likely to take place in families in the lowest socio-economic groups (classes D and $\mathrm{E}$ according to the economic classification) than in middle-income families (class B). Race/ethnicity also showed a strong association with HFI. Again, considering only the direct path, women who self-identified as nonwhites were about twice as likely to be food insecure than those characterizing themselves as white.

Demographic variables were also important risk factors for HFI. Having a child or adolescent in the household and not being married or cohabiting at the time of the interview increased the chance of HFI threefold and twofold, respectively. Conversely, the lower the level of social support, the higher was the HFI. It should be noted that these estimates refer only to the direct links between these variables and the outcome. It follows that the total relationship must be far greater, as the result of adding all of the mediated paths. 


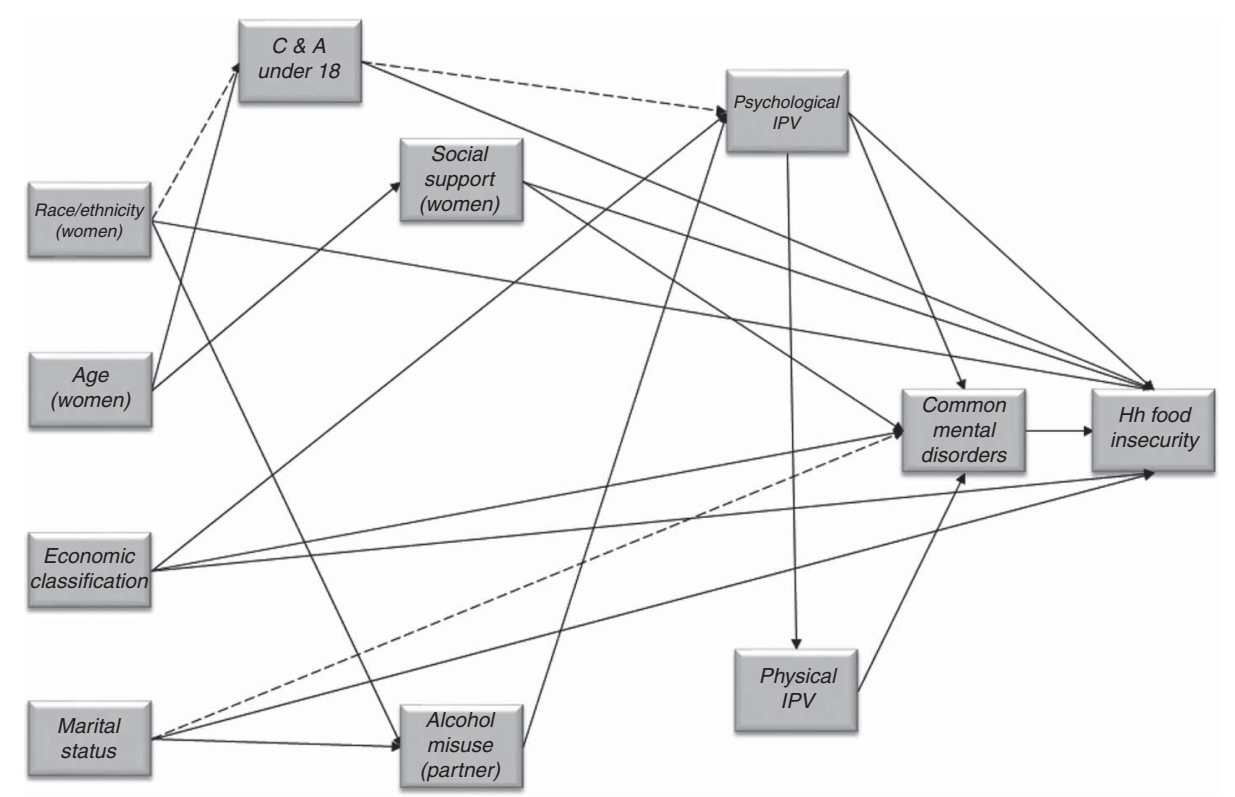

Fig. 2 'Final' model: directed acyclic graph of the relationships between intimate partner violence, common mental disorders and food insecurity ('Hh food insecurity', household food insecurity; 'Common mental disorders', common mental disorders in the woman; 'Psychological IPV', psychological intimate partner violence; 'Physical IPV', physical intimate partner violence; 'Alcohol misuse (partner)', alcohol misuse by the partner; 'Social support (women)', woman's social support; 'C \& A under 18', presence of children and adolescents under 18 years old in the household; 'Race/ethnicity (women)', woman's self-reported skin colour; 'Economic classification', Brazilian Economic Classification Criterion; 'Age (women)', woman's age)

Table 2 'Final model': point estimates, $95 \% \mathrm{Cl}$, statistical significance levels and fit index*

\begin{tabular}{|c|c|c|c|c|c|}
\hline \multicolumn{3}{|l|}{ Path } & \multirow{2}{*}{$\frac{\text { Point estimate }}{1.095}$} & \multirow{2}{*}{$\frac{95 \% \mathrm{Cl}}{1.037,1.157}$} & \multirow{2}{*}{$\frac{P \text { value }}{0.001}$} \\
\hline Common mental disorders & $\rightarrow$ & Hh food insecurity & & & \\
\hline Psychological IPV & $\rightarrow$ & Hh food insecurity & 1.095 & $1.015,1.182$ & 0.020 \\
\hline Social support (women) & $\rightarrow$ & Hh food insecurity & 0.917 & $0.875,0.962$ & 0.000 \\
\hline$C \& A$ under 18 & $\rightarrow$ & Hh food insecurity & 2.986 & $1.925,4.632$ & 0.000 \\
\hline Marital status & $\rightarrow$ & Hh food insecurity & 1.978 & $1.116,3.505$ & 0.020 \\
\hline Race/ethnicity (women) & $\rightarrow$ & Hh food insecurity & $2 \cdot 257$ & $1.319,3.861$ & 0.003 \\
\hline Economic classification & $\rightarrow$ & Hh food insecurity & 3.317 & $2 \cdot 084,5 \cdot 278$ & 0.000 \\
\hline Physical IPV & $\rightarrow$ & Common mental disorders & 0.424 & $0.094,4.495$ & 0.000 \\
\hline Psychological IPV & $\rightarrow$ & Common mental disorders & 0.244 & $0.104,2.353$ & 0.019 \\
\hline Social support (women) & $\rightarrow$ & Common mental disorders & -0.174 & $0.078,-2.218$ & 0.027 \\
\hline Marital status & $\rightarrow$ & Common mental disorders & 1.508 & $0.895,1.685$ & 0.092 \\
\hline Economic classification & $\rightarrow$ & Common mental disorders & 0.976 & $0.354,2.767$ & 0.006 \\
\hline Alcohol misuse (partner) & $\rightarrow$ & Psychological IPV & 1.818 & $1.371,2.411$ & 0.000 \\
\hline$C \& A$ under 18 & $\rightarrow$ & Psychological IPV & 1.751 & $0.997,3.072$ & 0.051 \\
\hline Economic classification & $\rightarrow$ & Psychological IPV & 1.584 & $1.039,2.414$ & 0.032 \\
\hline Physical IPV & $\rightarrow$ & Psychological IPV & 1.565 & $1.422,1.723$ & 0.000 \\
\hline$C \& A$ under 18 & $\rightarrow$ & Alcohol misuse (partner) & 1.910 & $1.127,3.236$ & 0.016 \\
\hline Marital status & $\rightarrow$ & Alcohol misuse (partner) & $6 \cdot 341$ & $2.923,13.752$ & 0.000 \\
\hline Race/ethnicity (women) & $\rightarrow$ & Alcohol misuse (partner) & 3.511 & $1.901,6.485$ & 0.000 \\
\hline Age (women) & $\rightarrow$ & Social support (women) & 0.050 & $0.017,2.949$ & 0.003 \\
\hline Age (women) & $\rightarrow$ & $C$ \& $A$ under 18 & 0.902 & $0.871,0.934$ & 0.000 \\
\hline Race/ethnicity (women) & $\rightarrow$ & $C \& A$ under 18 & 1.745 & $0.919,3.313$ & 0.088 \\
\hline Fit index (BIC) & & & & 18298.797 & \\
\hline
\end{tabular}

'Common mental disorders', common mental disorders in the woman; 'Psychological IPV', psychological intimate partner violence; 'Social support (women)', woman's social support; ' $\mathrm{C}$ \& A under 18', presence of children and adolescents under 18 years old in the household; 'Economic classification', Brazilian Economic Classification Criterion; 'Physical IPV', physical intimate partner violence; 'Alcohol misuse (partner)', alcohol misuse by the partner; 'Race/ethnicity (women)', woman's self-reported skin colour; 'Age (women)', woman's age; 'Hh food insecurity', household food insecurity; BIC, Bayesian information criterion. *Interpretations of paths' estimates according to outcome (incoming arrow): proportional odds ratio $\rightarrow$ 'Hh food insecurity', 'Psychological IPV', 'Physical IPV' and 'Alcohol misuse (partner)'; odds ratio $\rightarrow$ 'C \& A under 18'; linear regression coefficient $\rightarrow$ 'Common mental disorders' and 'Social support (women)'.

Two variables that showed rather different behaviour were women's age and alcohol misuse by the partner. The 'final' model suggested that the effects of both variables were completely mediated by other variables in the system and did not have a direct association by themselves. As maternal age increased, the degree of social support also 
rose, whereas the likelihood of having children or adolescents in the household diminished, thus reducing the likelihood of CMD and HFI by extension. Alcohol misuse by a partner seemed to be related only to psychological violence, which, as already mentioned, was connected to HFI through several pathways.

\section{Discussion}

Both psychological and physical violence were identified as significant risk factors of HFI. The prominence of psychological violence in the process was noticeable. Its connection to HFI seemed to occur through at least three different pathways. One went through physical violence and CMD, another was exclusively through CMD, and the third path linked psychological violence directly to HFI. This direct route suggests that there are other variables mediating this relationship beyond mental disorders and physical violence. A hypothesis could be that in relationships in which psychological violence is the norm, the partner tends to exert control over the family's budget as a means of establishing power and control over the woman, thus decreasing the priority of buying foodstuffs. This conjecture requires more in-depth discussion and research.

The notion that CMD precedes HFI also requires further research. Although backed by influential work in the scientific literature ${ }^{(15,37)}$, this directionality requires further insight because it is not universally held. Some authors postulate that HFI is actually a risk factor for affective disorders, rather than the opposite ${ }^{(38,39)}$. Clearly, both directions are acceptable and further analyses examining non-recursive and/or time-related longitudinal transition models could shed further light on the matter ${ }^{(40,41)}$.

However, in keeping with the original hypothesis suggested in the 'propositional' model, CMD seemed to function as a mediator between both types of violence and HFI. Again, this is consistent with the specific literature on the repercussions of IPV, of which mental disorders among women are considered one of the most important ${ }^{(15,42-44)}$. It is quite conceivable that the presence of these disorders affects women's motivations to buy and cook food. This demotivation could be related to the loss of appetite and apathy that is commonly expressed in CMD and/or to the physical and psychological exhaustion often felt by people experiencing domestic violence ${ }^{(45,46)}$. Another possibility is isolation. Women experiencing mental distress are less capable of seeking out help and support from government institutions designed to reduce HFI. In addition, there is the utilitarian hypothesis alluded to in the introduction according to which women exposed to violence and mental distress have more trouble getting and sustaining jobs or finishing school. Opportunities and adequate income thus progressively decrease, with insufficient diet ensuing as a long-term end result ${ }^{(10,47)}$.
From this perspective, the finding that CMD is a significant factor in the process between both types of violence and HFI suggests that HFI is not just a result of short financial means to buy food. Dysfunctional relationships in a family, with or without other psychosocial risk factors such as alcohol abuse or drug use, seem to play a relevant role too.

The effective link between psychological and physical IPV is also related to previous studies and theories. The first investigations in the USA by Straus and Gelles ${ }^{(48,49)}$ indicated that in most homes where there is physical violence, there is also a backdrop of psychological violence. Over the years, this finding has repeatedly recurred in the literature, continually underscoring the concomitance of different forms of violence in conflictive relationships within couples $^{(50)}$ and the fact that psychological violence almost always precedes physical abuse ${ }^{(51)}$.

Another noteworthy finding was that a low economic status was partially associated with HFI over psychological violence and increased mental disorders. This again indicates that in addition to the direct impact of low income on the means to buy food, part of the relationship could also be due to the greater vulnerability of these families to psychosocial stressors such as IPV and mental disorders. These findings reinforce the importance of considering more complex models that include different aspects of individuals' lives to better understand the situations leading to HFI. Following corroboration, it would be helpful for interventions designed to reduce HFI to not be restricted to macro-structural measures such as cash transfers to boost family budgets but to consider other approaches to address IPV and the resulting emotional vulnerability of those involved.

Interestingly, alcohol misuse by the partner was related to HFI only through psychological violence and its consequences. Based on this premise, it may well be that when food insecurity occurs in families in which the partner abuses alcohol there is also rampant psychological aggression, which, if not tackled, may spiral into physical violence, mental distress and ultimately more insecurity. The current results also support evidence from previous research reporting that non-white women rearing children or adolescents as single mothers are considerably more prone to food insecurity ${ }^{(52-55)}$. These findings reinforce the proposition that different manifestations of violence among those most vulnerable play a fundamental role in food insecurity, illustrating the need to address HFI through multi-tiered interventions implemented by different professionals and sectors ${ }^{(52-55)}$.

The results of the current study should be considered in the light of its strengths and weaknesses. Jointly studying psychological and physical IPV in a single model is a positive aspect of the study. Another strength may be the novelty of investigating the associations between these two forms of IPV and HFI mediated by maternal mental health. Use of causal graphs was a strength in this regard 
because it allowed for the estimation of indirect relationships in addition to direct associations. Path analysis was additionally relevant to show the associations with other economic, demographic and lifestyle-related antecedents. Another favourable methodological decision was the population-based sampling strategy employed that enabled representative prevalence estimates of the events of interest. The use of different validated epidemiological instruments to measure more complex constructs deserves mentioning, as this helped reduce the underestimation of events and misclassification bias to some extent ${ }^{(24,25,27)}$. Still, future studies should contemplate more complex structural equation models to better address measurement errors.

Using a cross-sectional approach could be considered a potential weakness. According to Gundersen and Ziliak $^{(41)}$, a causal relationship between food insecurity and other health outcomes in cross-sectional studies is not as clear. In principle, this data collection strategy cannot ensure that IPV precedes HFI. However, the 12-month time frame used to record violence should be extensive enough to represent events suffered over a long period of time, thereby covering habitual and persistent experiences of violent behaviour or victimization. The perspective that intimate violence is often a 'chronic' experience is grounded in the findings of several studies that reported that the time normally elapsing before a woman will end a violent relationship exceeds 10 years. Moreover, women who have suffered violence once tend to experience the same patterns of violence in subsequent relationships ${ }^{(50)}$. This tends to reinforce the hypothesis that the associations identified in the present study occur in mostly one direction, i.e. from left to right as conveyed in Fig. 2. However, some studies have noted that experiencing food insufficiency during childhood and adolescence could be a potential risk factor for depression and other mental health problems years later. To determine the directionality of this relationship would require a longitudinal study, which should be encouraged $^{(56,57)}$.

As noted in the introduction, epidemiological studies on this subject are still rare. The current research programme is still in its infancy and, as such, the 'final' model should be viewed only as a start. Although it is a refined version of the cruder 'propositional' model, it still requires improvements and many issues to be addressed. Further corroboration studies are needed. The associations proposed and identified in the present study not only need to be replicated but should be studied through increasingly comprehensive models as previously stated. Unobserved characteristics related to both HFI and IPV may be likely and would need to be controlled for. Moreover, adding other factors that are not yet explored could lead to improved explanations. How the types of violence studied here are related to sexual violence, community violence and illicit drug consumption are still issues needing answers.

A relevant question concerns whether the study findings would hold true in different population domains and contexts. Despite recent progress in increasing the true income of the poorest in Brazil, the present results seem to suggest that HFI is still a major public health problem. Its frequency in the population studied (approx. 40\%) is higher than the national estimate $(30 \cdot 2 \%)$ and the average identified in the State of Rio de Janeiro (28.3\%). The figures are more akin to those quoted for the north and north-east of the country ( $40 \cdot 3 \%$ and $46 \cdot 1 \%$, respectively), which are known as the poorest regions of Brazil ${ }^{(52)}$. IPV, a reality in many homes, is also an issue worth addressing. As mentioned earlier, approximately two-thirds of the women interviewed reported having been involved in at least one act of psychological violence in the 12 months prior to the interview and a quarter of the women had experienced physical violence in the same period. It is quite likely that the magnitude of these two phenomena originates from the poor socio-economic conditions typical of the areas to which the study population belong. Future studies should evaluate the reproducibility of the main findings presented here in areas characterized by a higher income and level of education.

Despite the limitations and gaps mentioned above, the results of the present study indicate - and reinforce, if considered in light of the related literature ${ }^{(4,5,8,10)}-$ the importance of IPV and CMD in models designed to understand the processes leading to HFI. Recognizing these factors in families at risk may provide professionals involved in direct assistance more latitude in potential interventions. The findings are of equal importance to managers and professionals responsible for public health policies, as the results may offer key elements that can support recent and innovative approaches to eliminating this serious public health problem, which have been strongly called for by agencies involved in comprehensive intersectorial efforts ${ }^{(58,59)}$.

\section{Acknowledgements}

Financial support: E.S.M. was partially supported by the Brazilian National Research Council (CNPq). C.L.M. was partially supported by the CNPq (grant number 302430/ 2011-3) and the Rio de Janeiro Research Foundation (FAPERJ) (grant number E 26/110·756/2010). M.E.R. was partially supported by the CNPq (grant number 301221/ 2009-0). The institutions contributed to the study design, conduct of the study, analysis of data, interpretation of findings and the preparation of the manuscript. Conflict of interest: None. Authorship: C.L.M. designed the study, supervised the data collection process, undertook the analysis and collaborated in writing the manuscript. E.S.M. collaborated in analysing the data and writing the final version of the manuscript. M.E.R. designed the study, supervised the data collection process, undertook the analysis and collaborated in writing the manuscript. M.F.F. collaborated in undertaking the literature review and in 
the data analysis. R.S.C. collaborated in designing the study, in supervising the data collection process and in writing the final version of the manuscript. All authors have read and approved the final manuscript. Ethics of buman subject participation: The research was approved by the Ethics Committee of the Federal University of Rio de Janeiro (protocol number 73/2009).

\section{References}

1. World Health Organization (2000) Millennium Development Goals (MDGs). http://www.who.int/topics/millennium development_goals/about/en/index.html (accessed September 2010).

2. Pérez-Escamilla R (2012) Can experience-based household food security scales help improve food security governance? Glob Food Sec 1, 120-125.

3. Food and Agriculture Organization of the United Nations (2013) The State of Food Insecurity in the World - The multiple dimensions of food security. http://www.fao.org/ docrep/018/i3434e/i3434e.pdf (accesed December 2013).

4. Melchior M, Caspi A, Howard LM et al. (2009) Mental health context of food insecurity: a representative cohort of families with young children. Pediatrics 124, e564-e572.

5. Hernandez DC, Marshall A \& Mineo C (2014) Maternal depression mediates the association between intimate partner violence and food insecurity. J Womens Health 23, 29-37.

6. Stuff JE, Casey PH, Szeto KL et al. (2004) Household food insecurity is associated with adult health status. J Nutr 134, $2330-2335$.

7. Tarasuk V, Mitchell A, McLaren L et al. (2013) Chronic physical and mental health conditions among adults may increase vulnerability to household food insecurity. $J$ Nutr 143, 1785-1793.

8. Chilton M \& Booth S (2007) Hunger of the body and hunger of the mind: African American women's perceptions of food insecurity, health and violence. J Nutr Educ Behav 39, 116-125.

9. Wehler C, Weinreb LF, Huntington N et al. (2004) Risk and protective factors for adult and child hunger among lowincome housed and homeless female-headed families. Am J Public Health 94, 109-115.

10. Chilton MM, Rabinowich JR \& Woolf NH (2014) Very low food security in the USA is linked with exposure to violence. Public Health Nutr 17, 73-82.

11. Ribeiro-Silva RdC, Fiaccone RL, Barreto ML et al. (2015) The association between intimate partner domestic violence and the food security status of poor families in Brazil. Public Health Nutr 19, 1305-1311.

12. Trevillion K, Oram S, Feder G et al. (2012) Experiences of domestic violence and mental disorders: a systematic review and meta-analysis. PLoS One 7, e 51740.

13. Dillon G, Hussain R, Loxton D et al. (2013) Mental and physical health and intimate partner violence against women: a review of the literature. Int J Fam Med 2013, 313909.

14. Reichenheim M, Moraes C, Lopes C et al. (2014) The role of intimate partner violence and other health-related social factors on postpartum common mental disorders: a surveybased structural equation modeling analysis. BMC Public Health 14, 427.

15. World Health Organization (2013) Global and Regional Estimates of Violence Against Women: Prevalence and Health Effects of Intimate Partner Violence and NonPartner Sexual Violence. Geneva: WHO.

16. Haldane JB (1945) On a method of estimating frequencies. Biometrika 33, 222-225.
17. Hirai WG \& Anjos FSd (2007) Estado e segurança alimentar: alcances e limitações de políticas públicas no Brasil. Textos Contextos 6, 335-353.

18. Associação Brasileira de Empresas de Pesquisa (2012) Critério de Classificação Econômica Brasil (CCEB). http:// www.abep.org/novo/Content.aspx?'ContentID=301 (accessed April 2012).

19. Instituto de Pesquisa Econômica Aplicada (2011) Retrato das Desigualdades de Gênero e Raça, 4th ed. Brasilia, DF: IPEA.

20. Chor D, Griep RH, Lopes CS et al. (2001) Social network and social support measures from the Pro-Saude Study: pretests and pilot study. Cad Saude Publica 17, 887-896.

21. Sherbourne CD \& Stewart AL (1991) The MOS social support survey. Soc Sci Med 32, 705-714.

22. Masur J \& Monteiro MG (1983) Validation of the 'CAGE' alcoholism screening test in a Brazilian psychiatric inpatient hospital setting. Braz J Med Biol Res 16, 215-218.

23. Mayfield D, McLeod G \& Hall P (1974) The CAGE questionnaire: validation of a new alcoholism screening instrument. Am J Psychiatry 131, 1121-1123.

24. Moraes CL \& Reichenheim ME (2002) Cross-cultural measurement equivalence of the Revised Conflict Tactics Scales (CTS2) Portuguese version used to identify violence within couples. Cad Saude Publica 18, 783-796.

25. Straus MA, Hamby SL, Boney-McCoy S et al. (1996) The Revised Conflict Tactics Scales (CTS2): development and preliminary psychometric data. J Fam Issues 17, 283-316.

26. Moraes CL, Hasselmann MH \& Reichenheim ME (2002) Adaptação transcultural para o português do instrumento 'Revised Conflict Tactics Scales (CTS2)' utilizado para identificar violência entre casais. Cad Saude Publica 18, 163-176.

27. Reichenheim ME, Klein R \& Moraes CL (2007) Assessing the physical violence component of the Revised Conflict Tactics Scales when used in heterosexual couples: an item response theory analysis. Cad Saude Publica 23, 53-62.

28. Mari JJ \& Williams P (1985) A comparison of the validity of two psychiatric screening questionnaires (GHQ-12 and SRQ-20) in Brazil, using relative operating characteristic (ROC) analysis. Psychol Med 15, 651-659.

29. Goldberg DP \& Williams P (1988) The User's Guide to the General Health Questionnaire. Windsor: NFER-Nelson.

30. Segall-Corrêa AM, Escamilla RP, Sampaio MdFA et al. (2004) Acompanhamento e Avaliação da Segurança Alimentar de Famílias Brasileiras: Validação de Metodologia e de Instrumento de Coleta de Informação. Urbano/Rural. [Relatório Técnico - Preliminar]. Campinas, SP: Universidade Estadual de Campinas/Organização PanAmericana da Saúde/Ministério de Saúde.

31. Bickel G, Nord M, Price C et al. (2000) Guide to Measuring Household Food Security - Revised 2000. Alexandria, VA: US Department of Agriculture, Food and Nutrition Service.

32. Marques ES, Reichenheim ME, de Moraes CL et al. (2015) Household food insecurity: a systematic review of the measuring instruments used in epidemiological studies. Public Health Nutr 18, 877-892.

33. Facchini LA, Nunes BP, Motta JV et al. (2014) Insegurança alimentar no Nordeste e Sul do Brasil: magnitude, fatores associados e padrões de renda per capita para redução das iniquidades. Cad Saude Publica 30, 161-174.

34. Muthén LK \& Muthén BO (1998-2016) Mplus User's Guide, 7 th ed. Los Angeles, CA: Muthén \& Muthén.

35. Schwarz G (1978) Estimating the dimension of a model. Ann Stat 6, 461-464.

36. Brown TA (2006) Confirmatory Factor Analysis for Applied Research. New York: The Guilford Press.

37. García-Moreno C \& Riecher-Rossler A (editors) (2013) Key Issues in Mental Health. vol. 178: Violence against Women and Mental Health. Basel: Karger Medical and Scientific Publishers. 
38. Hadley C \& Patil CL (2008) Seasonal changes in household food insecurity and symptoms of anxiety and depression. Am J Phys Anthropol 135, 225-232.

39. Vozoris NT \& Tarasuk VS (2003) Household food insufficiency is associated with poorer health. J Nutr $\mathbf{1 3 3}$, 120-126.

40. Sorsdahl K, Slopen N, Siefert K et al. (2011) Household food insufficiency and mental health in South Africa. J Epidemiol Community Health 65, 426-431.

41. Gundersen C \& Ziliak JP (2015) Food insecurity and health outcomes. Health Aff (Millwood) 34, 1830-1839.

42. Devries KM, Mak JY, Bacchus LJ et al. (2013) Intimate partner violence and incident depressive symptoms and suicide attempts: a systematic review of longitudinal studies. PLoS Med 10, e1001439.

43. Wong J \& Mellor D (2014) Intimate partner violence and women's health and wellbeing: impacts, risk factors and responses. Contemp Nurse 46, 170-179.

44. Reichenheim ME, Moraes CL, Lopes CS et al. (2014) The role of intimate partner violence and other psychosocial events on postpartum common mental disorders: a survey-based structural equation modeling analysis. BMC Public Health 14, 427.

45. Marazziti D, Consoli G, Picchetti M et al. (2010) Cognitive impairment in major depression. Eur J Pharmacol 626, 83-86.

46. National Institutes of Health, National Institute of Mental Health (2002) Depression. https://www.nimh.nih.gov/ health/topics/depression/index.shtml (accessed April 2012).

47. Chilton M, Knowles M, Rabinowich J et al. (2015) The relationship between childhood adversity and food insecurity: 'It's like a bird nesting in your head'. Public Health Nutr 18, 2643-2653.

48. Straus MA, Gelles RJ \& Steinmetz SK (1980) Behind Closed Doors: Violence in the American Family. New York: Doubleday/Anchor Press.

49. Straus MA \& Gelles RJ (1995) Physical Violence in American Families: Risk Factors and Adaptations to Violence in 8145 Families. New Brunswick, NJ: Transaction Publishers.
50. Krug EG, Dahlberg LL, Mercy JA et al. (2002) World Report on Violence and Health. Geneva: WHO.

51. Gellert GA (2010) Confronting Violence: Answering Questions about the Epidemic Destroying America's Homes and Communities, 3th ed. Washington, DC: American Public Health Association.

52. Instituto Brasileiro de Geografia e Estatística (2010) Pesquisa Nacional por Amostra de Domicílios - Segurança Alimentar 2004/2009. Rio de Janeiro, RJ: IBGE.

53. Gundersen C \& Gruber J (2001) The dynamic determinants of food insufficiency. In Second Food Security Measurement and Research Conference. vol. 2: Papers, pp. 91-109. Food Assistance and Nutrition Research Report no. FANNR-11-2. Washington, DC: US Department of Agriculture, Economic Research Service.

54. Daponte BO \& Stephens M (2004) The Relationship between Food Assistance, the Value of Food Acquired, and Household Food Security. Working Paper \#04.08. Chicago, IL: The University of Chicago, Irving B. Harris Graduate School of Public Policy; available at http://www.ibrarian.net/navon/ page.jsp?paperid=16112972\&searchTerm=household+food

55. Food and Agriculture Organization of the United Nations (2009) The State of Food Insecurity in the World. Economic crises - impacts and lessons learned. ftp://ftp.fao.org/docrep/ fao/012/i0876e/i0876e.pdf (accessed December 2013).

56. Alaimo K, Olson CM \& Frongillo EA (2002) Family food insufficiency, but not low family income, is positively associated with dysthymia and suicide symptoms in adolescents. J Nutr 132, 719-725.

57. McIntyre L, Williams JVA, Lavorato DH et al. (2013) Depression and suicide ideation in late adolescence and early adulthood are an outcome of child hunger. $J$ Affect Disord 150, 123-129.

58. Organização Pan-Americana da Saúde \& Organização Mundial da Saúde (2010) Prevenção da Violência Sexual e da Violência pelo Parceiro Intimo Contra a Mulher: Ação e Produção de Eviência. Washington, DC: OPAS/OMS.

59. World Health Organization (2014) Global Status Report on Violence Prevention 2014. Geneva: WHO. 